\title{
Abnormal central venous oxygen saturation in cardiac surgery patients: a prospective, observational study
}

\author{
D Unic-Stojanovic ${ }^{1 *}$, P Vukovic ${ }^{1}$, D Nezic ${ }^{1}$, M Filipovic ${ }^{1}$, P Milojevic ${ }^{1,2}$, M Jovic ${ }^{1,2}$ \\ From 23rd World Congress of the World Society of Cardio-Thoracic Surgeons \\ Split, Croatia. 12-15 September 2013
}

\section{Background}

Central (ScVO2) and mixed venous oxygen saturation $(\mathrm{SvO} 2)$ and blood lactate are useful measurement tools for evaluating the degree of hypoperfusion in patients with different disease processes. The aim was to study incidence of both low as well as high $\mathrm{ScvO} 2$ and assessed their relationship to markers of tissue hypoxia, course and outcome in patients undergoing elective cardiac surgery.

\section{Materials and methods}

Prospective, observational study. Settings: A 22-bed heart surgery intensive care unit (ICU) in a tertiary university hospital. Postoperative blood samples for the measurement of ScvO2 and lactate were obtained on arrival, 8 and 24 hours after ICU admission. 54 patients were divided into 3 groups based on $\mathrm{ScvO} 2$ values upon admission to the ICU: low, normal and high ("supranormal") ScvO2 group. Data analysis was performed using the SPSS software package, version 20.0.

\section{Results and discussion}

Total number of patients included in the study was 54 (41 males, 13 females), average age of $61.7 \pm 9.7$ years old. Abnormal ScvO2 were recorded in 34/54 (62.9\%) patients. A low ScvO2 $(<60.5)$ was recorded in 21 (38.8\%) and high ScvO2 (> 72.1) was recorded in 13 (24.1\%) patients. While heart rates and central venous pressure were comparable between groups at all time points, mean arterial pressure was lower in the high $\mathrm{ScvO} 2$ group in comparison with the low and normal
$\mathrm{ScvO} 2$ group. In the supranomal $\mathrm{ScvO} 2$ group there were higher lactate values, blood glucose levels, white blood cell count and the use of inotropes, so as prolonged ICU and hospital stay, compered to normal $\mathrm{ScvO} 2$ group.

\section{Conclusions}

Supranormal values of ScvO2, which are traditionally considered to be of limited clinical value, turned out to be under-recognized warning signs of impaired tissue oxygenation in cardiac surgery patients. Further studies are necessary to assess the utility of $\mathrm{ScvO} 2$ and lactate to guide hemodynamic optimization and the impact it has on morbidity and mortality.

\section{Authors' details}

${ }^{1}$ Cardiovascular Institute Dedinje Belgrade, Serbia. ${ }^{2}$ Medical faculty Belgrade, Serbia.

Published: 11 September 2013

doi:10.1186/1749-8090-8-S1-0163

Cite this article as: Unic-Stojanovic et al:: Abnormal central venous oxygen saturation in cardiac surgery patients: a prospective, observational study. Journal of Cardiothoracic Surgery 2013 8(Suppl 1): 0163.

* Correspondence: dunic@yubc.net

${ }^{1}$ Cardiovascular Institute Dedinje Belgrade, Serbia

Full list of author information is available at the end of the article 